\title{
CORTICAL AFFERENT INPUT TO THE PRINCIPALS REGION OF THE RHESUS MONKEY
}

\author{
H. BARBAS and M-M. MESULAM \\ Departments of Health Sciences and Anatomy, Boston University and School of Medicine, \\ 36 Cummington St. B-11, Boston, MA 02215, U.S.A.; and the Bullard and Denny-Brown \\ Laboratories of the Harvard Neurological Unit, Beth Israel Hospital and the Charles A. Dana \\ Research Institute, 330 Brookline Avenue, Boston, MA 02215, U.S.A.
}

\begin{abstract}
The sources of ipsilateral cortical afferent projections to regions along both banks of the principalis sulcus in the prefrontal cortex were studied with horseradish peroxidase in macaque monkeys. The principalis cortex receives a substantial proportion of its projections from neighboring prefrontal regions. However, differences were noted in the distribution of labeled cells projecting to the various principalis regions. These differences were most marked with respect to the relative proportion of cells originating in visual, auditory, somatosensory, premotor and limbic cortical areas. The findings indicate that the caudal ventral principalis region receives projections from both visual and visuomotor regions, whereas the anterior tip of the principalis appears to be the major target of projections from auditory association regions. The ventral bank at the middle extent of the principalis was the only case with a significant proportion of labeled cells in somatosensory association and premotor regions. There was a consistent increase in the proportion of labeled cells in limbic cortical areas projecting to more rostral principalis sites, irrespective of whether the injection was placed in the dorsal or ventral bank.

These findings suggest that the caudal principalis region has a visual-visuomotor and the rostral, an auditorylimbic bias with respect to the long projections they receive.
\end{abstract}

The dorsolateral prefrontal cortex of the rhesus monkey extends from the arcuate sulcus to the frontal pole. It is a cytoarchitectonically complex region and in Walker's $^{91}$ classification it encompasses areas 8,45, 46,12, 9 and 10 (Fig. 1 A). The dorsolateral prefrontal cortex may be functionally divided into peri- and prearcuate regions. The former is coextensive with the frontal eye fields (areas 8 and 45); the latter includes the rest of the dorsolateral prefrontal cortex and will be the focus of this report.

The prearcuate cortex of the monkey receives a variety of neural projections from visual, auditory, polymodal and limbic cortical regions. ${ }^{1026,28,62}$ In accordance with these anatomic connections, neurons in the prearcuate region respond to visual and auditory stimuli and dorsolateral cortical ablation results in disruption of tasks involving visual and auditory discrimination. ${ }^{3 J_{1} 81,94}$ Because of its anatomic connections and physiologic properties, the dorsolateral cortex has hitherto been considered as a large polymodal region. However, very few dorsolateral neurons are truly polysensory, with the majority responding either to visual or auditory stimuli, but not both. ${ }^{24}-_{-}{ }^{-39}$ In addition to this partial segregation of modalities at the single-cell level, there are also regional variations within the dorsolateral prefrontal cortex, as demonstrated by physiologic and behavioral studies. For example, even though the prearcuate cortex lining the principal sulcus has been

considered essential for tasks based on delayed responses $^{47,19,20,25,59,79} 8{ }^{86}$ there is evidence that it is the middle third $^{9,56}$ and the caudal part ${ }^{85}$ of the banks of the principal sulcus which are crucial for the performance of these tasks. Consistent with these behavioral findings, it has been reported that neurons in the middle and caudal principalis regions fire in association with delayed response tasks. $33,37,38,63,92$ The above findings suggest that the prearcuate cortex is a heterogeneous region but the anatomic basis of these differences is not known. In a previous study we showed that subdivisions of the periarcuate frontal eye fields received markedly different projections, in a pattern which correlated with the physiologic properties of the subregions involved. ${ }^{2}$ The purpose of the present study was to investigate the organization of afferent input to subdivisions of a narrow strip of the dorsolateral prefrontal cortex extending from the caudal tip of the principalis sulcus to its most rostral extent in the frontal pole employing small injections of horseradish peroxidase (HRP).

\section{EXPERIMENTAL PROCEDURES}

Experiments involving HRP injections were conducted on five rhesus monkeys (Macaca mulatta $\backslash$ anesthetized with sodium pentobarbital (35mg/kgi.p.). Surgery was performed under aseptic conditions. The monkey's head was firmly positioned in a holder which left the cranium unobstructed for surgical approach. The femoral vein was catheterized for infusion of mannitol (Invenenx, Ohio, 25\%) to reduce the volume of the brain and avoid traumatic edema. A bone defect was made, the dura was retracted and the cortex exposed.

Abbreviation: HRP, horseradish peroxidase. 

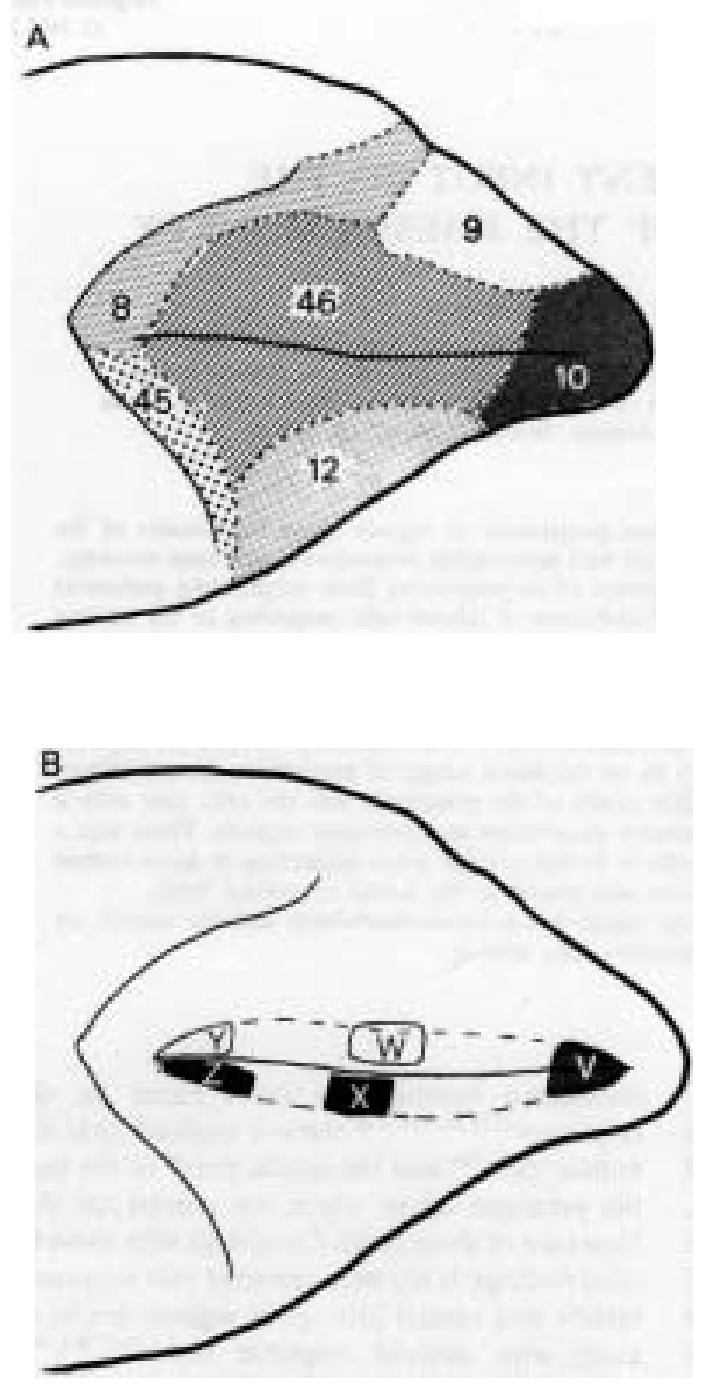

Fig. 1. (A) Diagram of the monkey dorsolateral frontal cortex showing Walker's ${ }^{91}$ cytoarchitectonic subdivisions. Areas 8 and 45 constitute the frontal eye fields. The prearcuate dorsolateral cortex includes area 46 and parts of areas 9,10 and 12. (B) Composite of the core of the HRP injection sites in the five cases.

Injections of HRP (Miles, 20\% aqueous solution) were made with a microsyringe (Hamilton, $75 \mathrm{~N}, 5 / \mathrm{il}$ ) mounted on a microdrive which was attached to a carrier (Kopf). The needle was lowered to the desired site under microscopic guidance. Small amounts $(0.05 / \mathrm{il})$ of the injectate were delivered $1.5 \mathrm{~mm}$ below the pial surface at each of 1-2 adjacent sites separated by $1-2$ $\mathrm{mm}$ over a $30 \mathrm{~min}$ period. The frontal regions injected with HRP extended along both banks of the principalis sulcus in a caudorostral direction (Fig. IB, Z-V).

Following a 40-48 $\mathrm{h}$ survival period the monkeys were reanesthetized and perfused through the heart with saline until the blood was cleared. A timed fixation procedure then followed, during which 21 of fixative (1.25\% glutaraldehyde, $1 \%$ paraformaldehyde in $0.1 \mathrm{M}$ phosphate buffer at $\mathrm{pH}$ 7.4) were delivered over a $30 \mathrm{~min}$ period. The fixative was followed by perfusion with 21 of cold $\left(4^{\mathrm{C}} \mathrm{C}\right)$ sucrose phosphate buffer $(10 \%$ sucrose in $0.1 \mathrm{M}$ phosphate buffer, $\mathrm{pH}$ 7.4). The latter was used to wash excess, unbound fixative from the tissue. This procedure allows regulation of the duration of fixation and prevents loss of HRP activity as a result of excessive exposure to aldehydes. ${ }^{76}$

The brain was then removed from the skull, photographed, placed in sucrose buffer and transferred to a freezing microtome, where,, it was cut at $40 \mu \mathrm{m}$. Sections were collected in a $0.1 \mathrm{M}$ phosphate buffer ( $\mathrm{pH}$ 7.4). Every 10th section was reacted for the visualization of HRP according to a procedure in which tetramethylbenzidine is used as the chromogen. The tissue was mounted, dried and counterstained with neutral red. ${ }_{-5}^{52}$

\section{Data analysis}

Experimental slides prepared according to the method described above were viewed microscopically under brightfield illumination. Outlines of brain sections and the location of labeled cells ipsilateral to the injection site were transferred from the slides onto paper using an $X-Y$ recorder (Hewlett Packard, 7044A) which was electronically coupled to the stage of the microscope. The extent of the injection site was outlined on the same paper. The area containing dark reaction-product, where neither cells nor axons were distinguishable, was considered as the injection core (Fig. 2). The less densely labeled area surrounding this region was drawn as the halo of the injection site. The laminar distribution of labeled cells was also noted on the plotting.

All of the prepared slides were examined but only representative sections (usually every other) among those containing labeled neurons were charted. If adjacent sections differed in the distribution of labeled neurons, then both sections were charted. Labeled neurons (represented as dots on the charted hemisphere which was drawn 8.5 times its actual size) were counted directly from the charted material in serial sections.

Procedural variables, such as size of the injection site, exposure of the tissue to alcohol, etc., inadvertently differ from case to case. In order to minimize the above extrinsic factors, the relative afferent input to the injected site from a particular anatomic region was assessed by expressing the number of labeled cortical cells in serial sections through that anatomic region as a percentage of the total number of labeled cortical cells in that case. This analysis is based on the assumption that histochemical variables underlying HRP sensitivity affect all cortical regions in that case in a similar manner. It is then possible to demonstrate qualitative differences in the pattern of regional labeling among cases without making direct statistical comparisons.

Labeled cells in the immediate vicinity of the injection site (within $0.5 \mathrm{~mm}$ radius from the halo of the injection, extending up to $1.6 \mathrm{~mm}$ anterior to the rostral and $1.6 \mathrm{~mm}$ posterior to the caudal limits of the injection site) were not included in the calculation of the total number of labeled cortical cells for each case. Although neurons in this vicinity might have been labeled through retrograde transport of HRP and could thus constitute local projections, the presence of a background saturated with reaction-product raised the possibility of labeling through direct spread of HRP from the injection site. Anterogradely transported enzyme was also observed in many cortical sites but this was not charted for this study.

The projection sites were serially reconstructed using the sulci as landmarks and were shown on diagrams of the surface of the cortex. The latter were drawn from photographs of each brain showing the external morphology of the experimental hemispheres. The drawings were modified to represent the relative location of cells buried in sulci.

The determination of cytoarchitectonic boundaries of regions containing labeled neurons was facilitated by viewing the experimental sections with a green filter. To determine the cytoarchitecture of the segment of the principalis region injected with HRP, a series of matched sections 
through the injection site was stained with cresyl violet. The results were compared to those obtained by examining the cytoarchitectonic features of two normal monkey cerebra embedded in celloidin, cut in 40 /im sections and stained with cresyl violet.

\section{RESULTS}

\section{Injection sites}

The injection sites covered the dorsal and ventral banks of the principal sulcus at its rostral, middle and caudal extent. In two monkeys the core of the injection site was situated in the dorsal and ventral bank of the posterior quarter of the principal sulcus, respectively (Fig. IB, Y and Z). In two other animals the injection site occupied the dorsal and ventral bank of the middle third of the principal sulcus, respectively (Fig. IB, W and $\mathrm{X}$ ). The injection site was restricted to only one bank of the principal sulcus in the above cases. However, in case Z, in an intended injection into the caudal ventral bank of the principalis, there was a slight invasion of the dorsal bank. In a fifth monkey the injection site encompased the rostral quarter of the principalis. In this case, where the banks of the sulcus are shallow, and the cytoarchitecture is uniform, the core of the injection site occupied both banks (Fig. IB, V).

Intact axons in the white matter are not thought to take up HRP. ${ }^{4151}$ In all cases in this study the needle tracts were restricted to the cortical mantle and there was no apparent damage to the underlying white matter. Thus although some reaction-product was noted to extend to the intact white matter underlying the injection site, this is not likely to have contributed to the final pattern of transport.

\section{Cortical projections}

Cortical regions where labeled neurons were noted following HRP injections in the five principalis regions are shown on the surfaces of the brain and in cross-sections in Figs 3-7. Labeled cortical cells were noted in peristriate and inferior temporal areas, the inferior parietal lobule and medial parietal cortex, the superior temporal gyrus and banks of the superior temporal sulcus, the parietal operculum, in prefrontal and premotor regions, the insula, the ventral bank of the lateral fissure and the cingulate and retrosplenial cortex. These results are consistent with previous findings. ${ }^{10} 2628.42$

The above cortical regions may be included in one of the following functional classes: visual, auditory, somatosensory, high-order association, premotor and limbic. The inclusion of regions with labeled neurons in one of these categories was made on the basis of two or more of the following criteria: (1) cytoarchitectonic characteristics; (2) patterns of neural connectivity based on anatomic experiments; (3) behavioral experiments describing deficits in various tasks following regional damage; and (4) electrophysiological studies on the properties of neurons in specific cortical regions.
There were differences in the distribution of cells projecting to the five principalis sites. These differences were most marked with respect to the relative proportion of labeled cells in visual, auditory, somatosensory, premotor and limbic cortical areas projecting to each site. The only site with a significant proportion of projections from visual association areas was the ventral bank of the caudal principalis region (Fig. IB, Z), whereas the rostral site (Fig. IB, $\mathrm{V})$ had the highest proportion of projections from auditory association areas. The ventral bank at the middle extent of the principalis (Fig. 1B, X) was the only site with a significant proportion of labeled cells in somatosensory association and premotor (area 6) regions. There was a consistent increase in the proportion of labeled cells in limbic cortical areas projecting to more rostral sites, irrespective of whether the HRP injection was situated in the dorsal or ventral bank of the principalis. To show the differences and similarities in the projection pattern in the five cases, direct comparisons will be made among the cases for each functional category of regions below.

\section{Visual association}

Areas 17, 18, and 19 of Brodmann, ${ }^{8}$ or OC, OB and OA of Von Bonin and Bailey, ${ }^{90}$ and the inferior temporal cortex (areas 20, 21 or TE) have been implicated in visual function on the basis of behavioral, anatomic and electrophysiologic experiments (for reviews see Refs 88, 89, 95 and 98). In the present experiment labeled neurons were found in areas $\mathrm{OA}$ and TE. Labeled neurons within peristriate areas were noted in the banks of the parieto-occipital sulcus on the medial surface of the brain and the adjacent cortical regions and anterior to the lunate sulcus on the dorsolateral surface of the brain. The above regions are included in areas V3 and V4 according to a more recent classification of the visual cortex. ${ }^{89} 95.98$ Within the inferior temporal cortex neurons projecting to the principalis cortex were situated in the rostral half of the ventral bank and depths of the superior temporal sulcus and in the adjacent lateral cortex.

Labeled neurons in peristriate and inferior temporal visual association regions were noted following injection in the ventral bank of the caudal $(6 \%)$ and ventral bank of the middle (1\%) and a few (less than $0.5 \%$ ) were noted following HRP injection in the mid-dorsal extent of the principalis. There was no evidence of labeled cells in visual association regions when the banks of the rostral tip or the caudal dorsal bank of the principalis were injected with HRP (Table 1, Figs 3-7).

\section{Visuomotor}

The inferior parietal lobule and the adjacent bank of the intraparietal sulcus have been considered as a cytoarchitectonic unit and were designated as area PG by Von Bonin and Bailey. ${ }^{90}$ Physiologic studies 

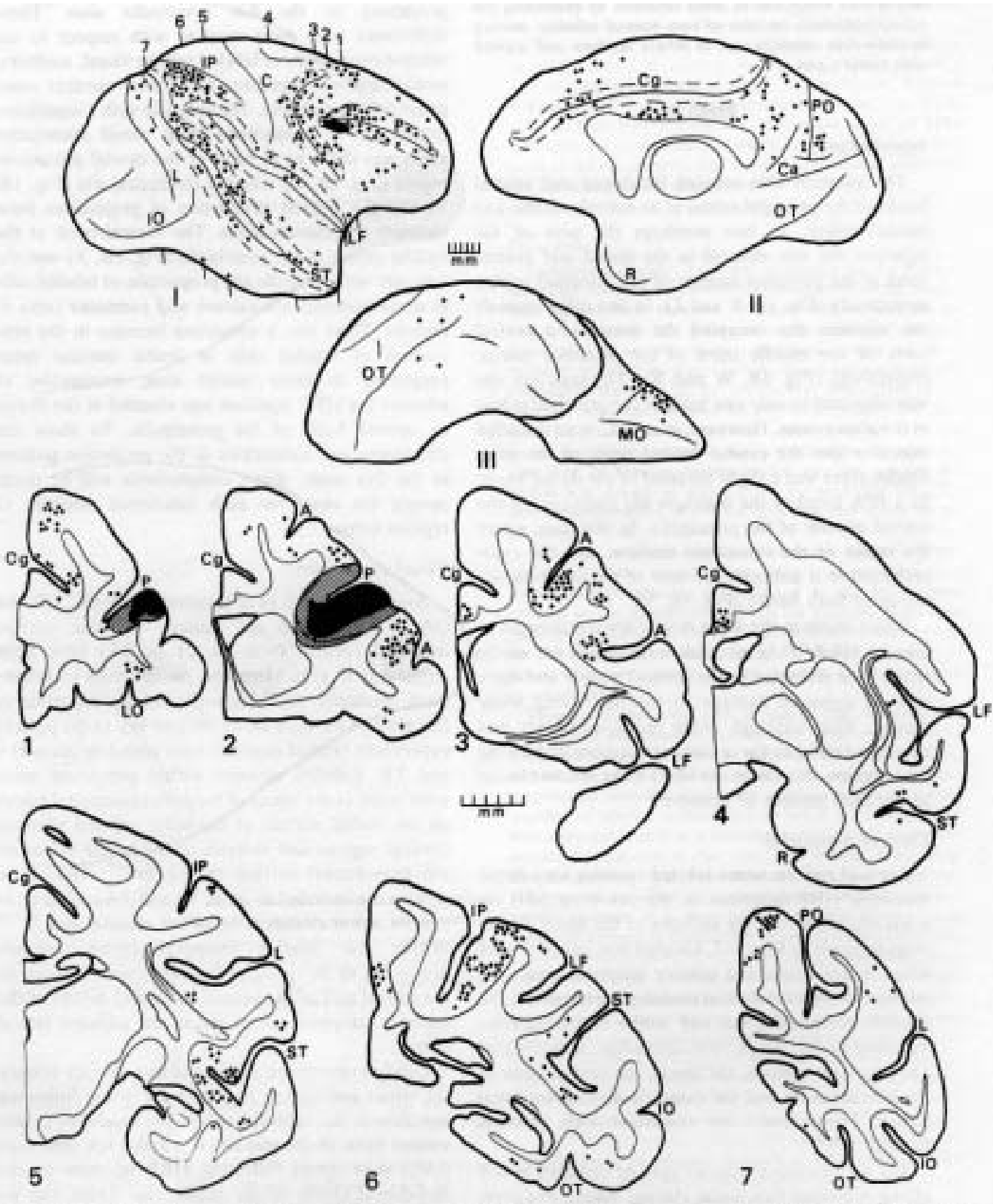

Fig. 3. I, lateral. II, medial and III, ventral view, of a brain in which a caudal ventral principals region was injected with HRP. The core of the injection site is shown in black on the lateral view, and labeled neurons are shown as black diamonds. The dotted lines represent the banks of sulci and the islands drawn in uninterrupted lines represent the cortex in the depths of the lateral fissure and the superior temporal sulcus. The density of the black diamonds represents the relative distribution of labeled neurons in each cortical region. Coronal sections taken at the level indicated on the dorsolateral surface show the core (black area) and halo (striped area) of the injection site, and the distribution of labeled neurons. These conventions apply for Figs 3-7. For quantitative distribution of labeled neurons by region, see Table 1. In this case there were labeled neurons in visual, auditory, visuomotor (ventral bank of intraparietal sulcus), in posterior and anterior high-order association and in limbic cortical regions. 

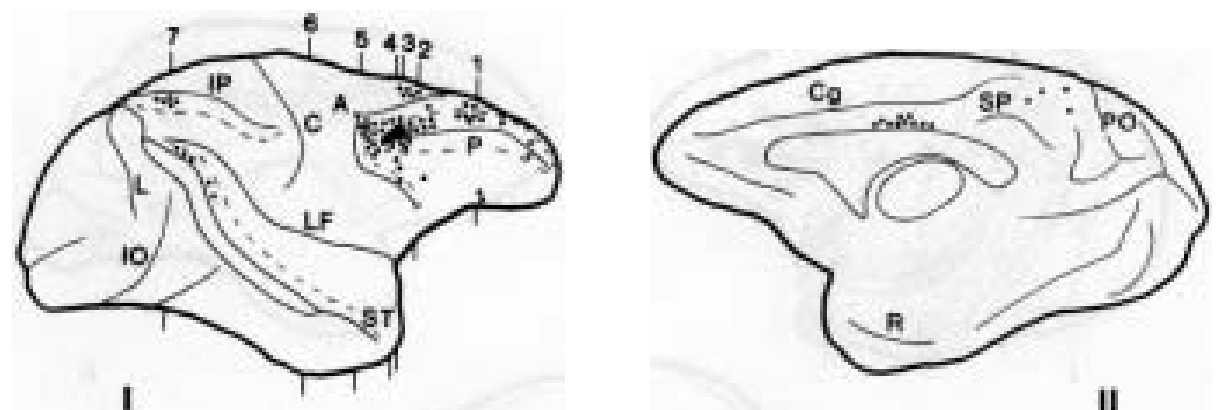

I

II
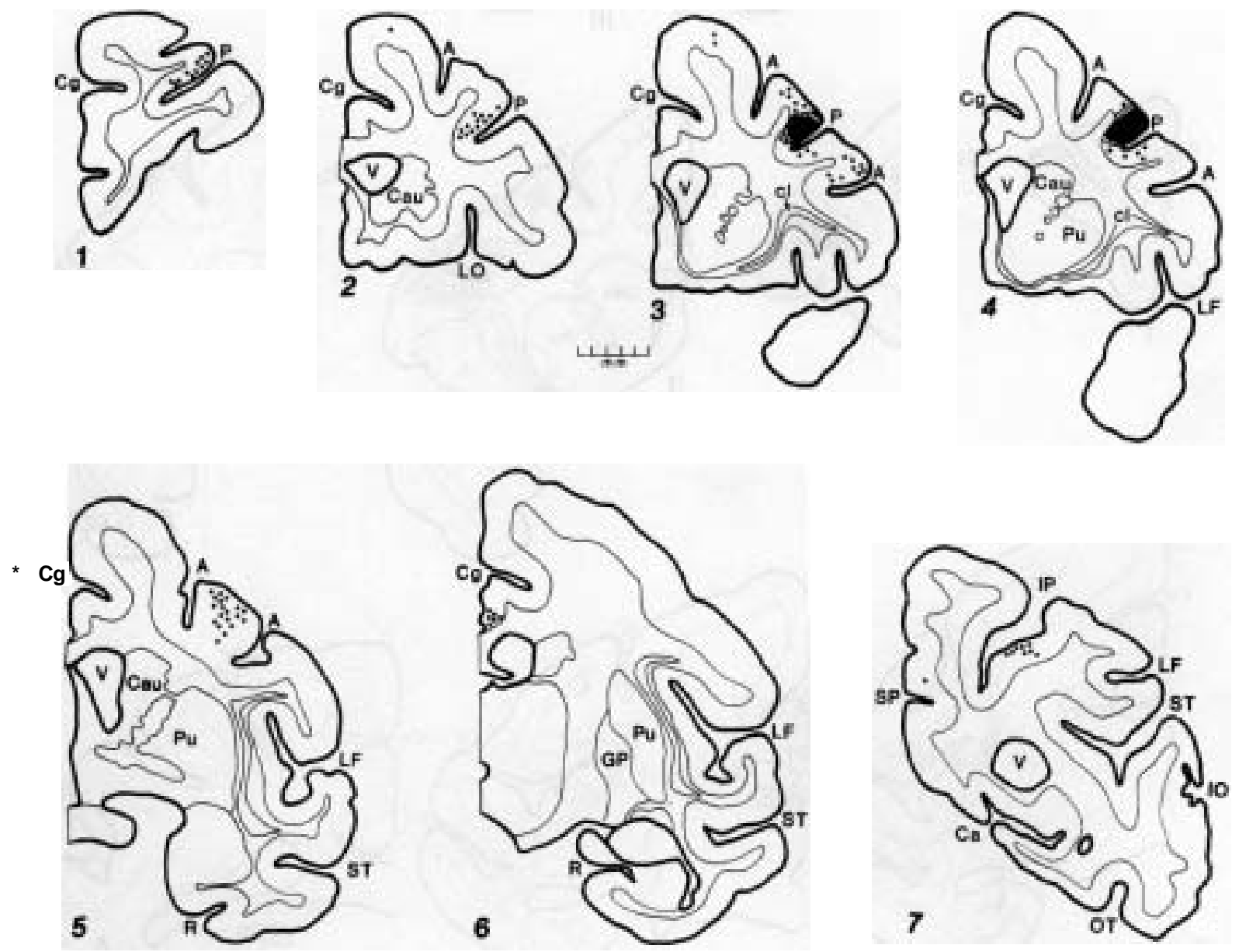

Fig. 4. I, lateral and II, medial view, of a brain in which the caudal dorsal principalis cortex was injected with HRP. Coronal sections 1-7 were taken at the level indicated on the dorsolateral surface and are shown below the views of the whole brain. In this case most labeled neurons were noted in rostral highorder association regions and a few were also noted in the ventral bank of the intraparietal sulcus, in cingulate cortex and auditory association regions. 


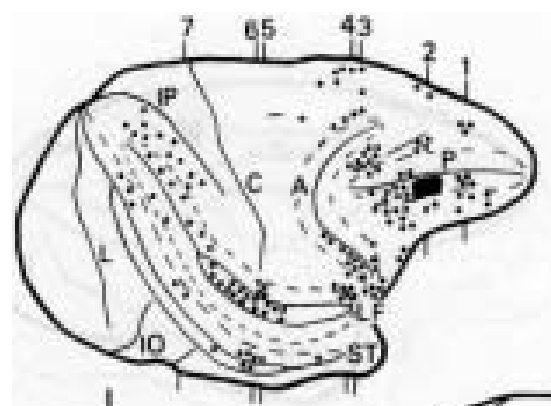

I

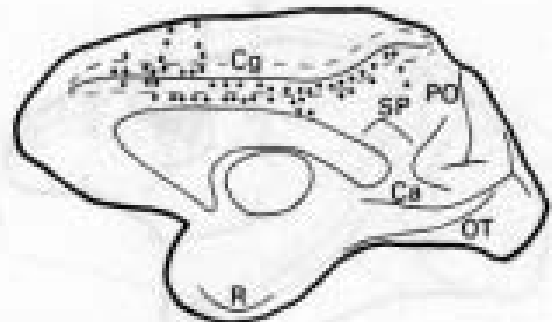

II
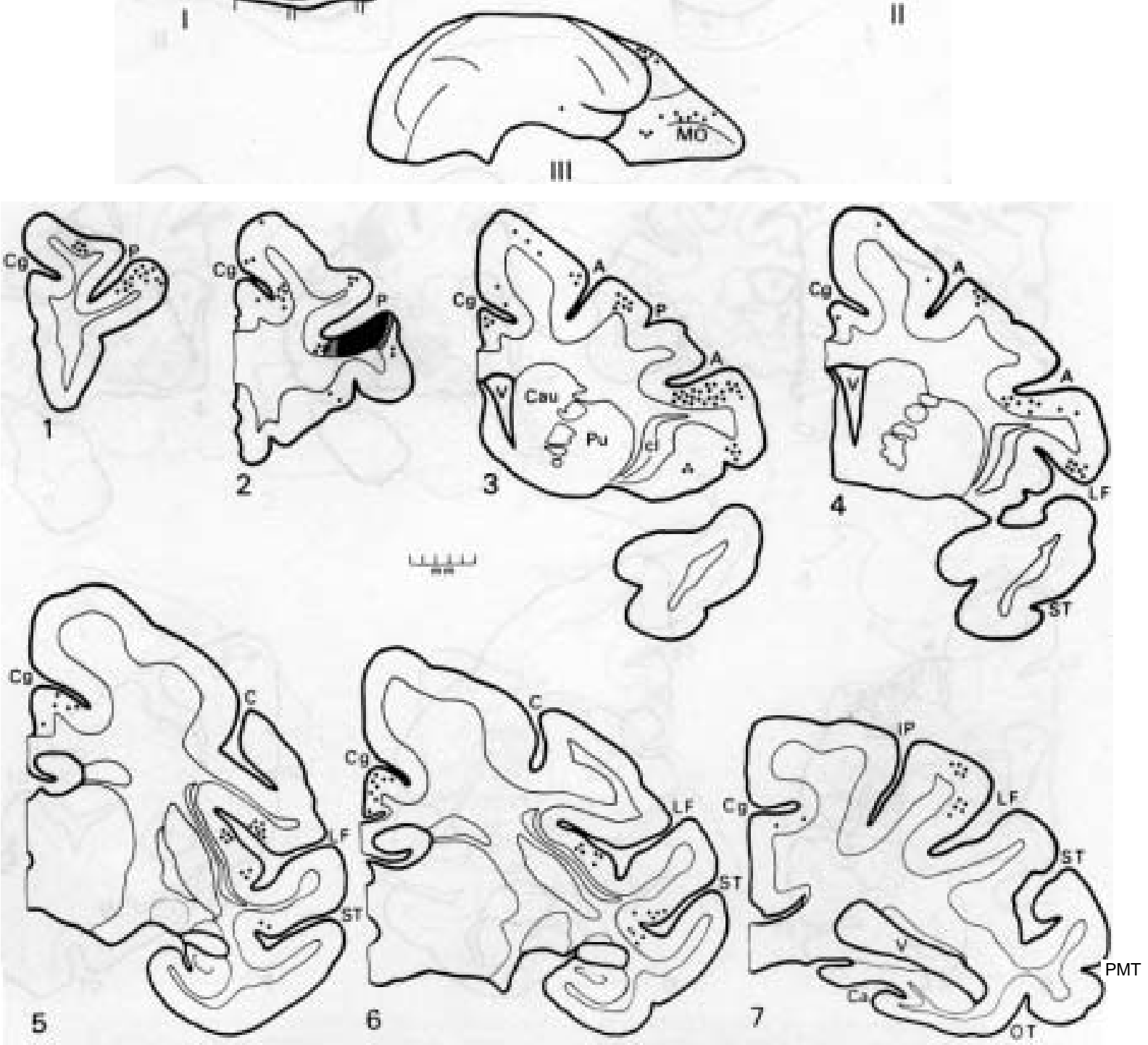

Fig. 5. I, lateral, II, medial and III, ventral views of a brain in which the mid-ventral principalis cortex was injected with HRP. Coronal sections 1-7 were taken at the level indicated on the dorsolateral surface and are shown below the views of the whole brain. In this case a significant proportion of all projecting neurons were situated in somatosensory association and in premotor regions. Labeled neurons were also noted in the inferior parietal lobule, anterior high-order association and limbic cortical regions, including the cingulate and orbitofrontal cortices. 

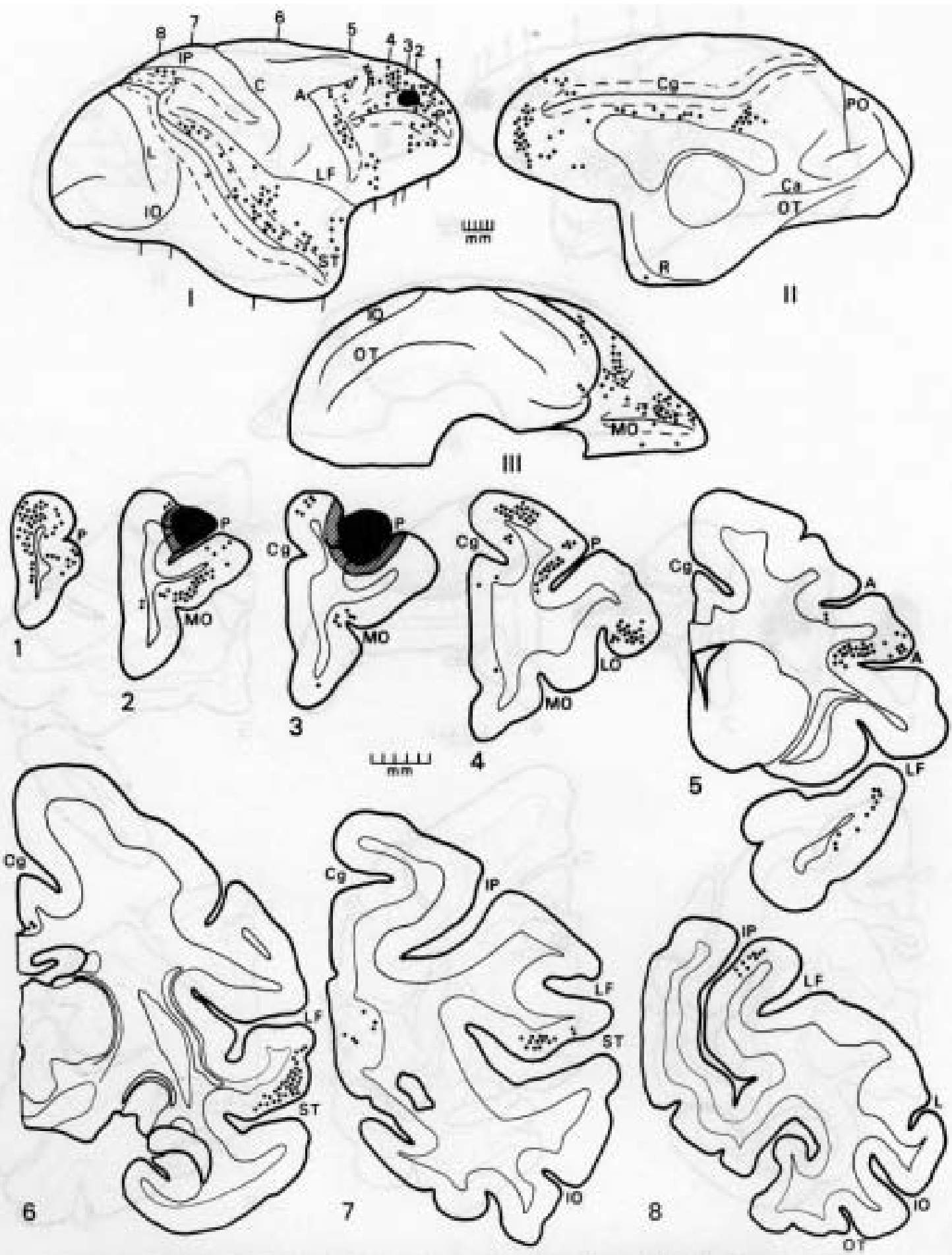

Fig. 6. I, lateral, II, medial and III, ventral views of a brain in which the mid-dorsal principalis region was injected with HRP. Coronal sections 1-8 were taken at the level indicated on the dorsolateral surface and are shown below the views of the whole brain. In this case labeled neurons were concentrated in auditory association, anterior and posterior high-order association and limbic cortical regions. A few labeled cells were noted in the ventral bank of the intraparietal sulcus and very few in the insu^a and ventral bank of the superior temporal sulcus (inferior temporal visual association region). 

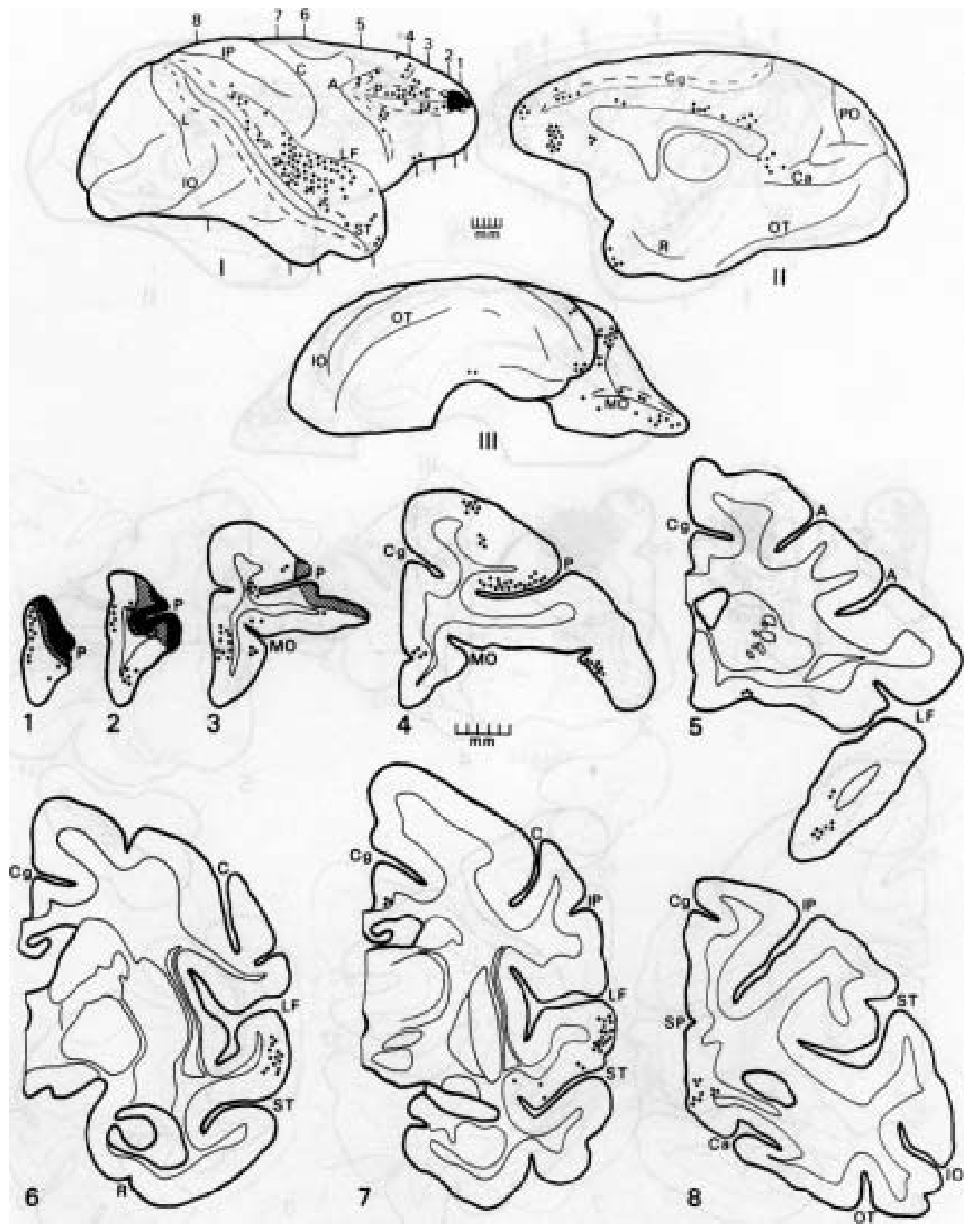

Fig. 7. I, lateral, II, medial and III, ventral view of a brain in which the rostral principalis region was injected with HRP. Coronal sections 1-8 were taken at the level indicated on the dorsolateral surface and are shown below the views of the whole brain. In this case there were more labeled neurons in auditory association and limbic cortical regions than in the other four. Labeled neurons were also seen in anterior and posterior high-order association regions. There was no evidence of labeled neurons in visual association areas in this case. 
Abbreviations used in figures

$\begin{array}{ll}\text { A } & \text { arcuate sulcus } \\ \text { C } & \text { central sulcus } \\ \text { Ca } & \text { calcarine fissure } \\ \text { Cau } & \text { caudate nucleus } \\ \text { Cg } & \text { cingulate sulcus } \\ \text { cl } & \text { claustrum } \\ \text { GP } & \text { globus pallidus } \\ \text { IO } & \text { inferior occipital sulcus } \\ \text { IP } & \text { intraparietal sulcus } \\ \text { L } & \text { lunate sulcus } \\ \text { LF } & \text { lateral fissure }\end{array}$

$\begin{array}{ll}\text { LO } & \text { lateral orbital sulcus } \\ \text { MO } & \text { medial orbital sulcus } \\ \text { OT } & \text { occipitotemporal sulcus } \\ \text { P } & \text { principal sulcus } \\ \text { PMT } & \text { posterior middle temporal sulcus } \\ \text { Pu } & \text { putamen } \\ \text { PO } & \text { parieto-occipital sulcus } \\ \text { R } & \text { rhinal sulcus } \\ \text { SP } & \text { subparietal sulcus } \\ \text { ST } & \text { superior temporal sulcus } \\ \text { V } & \text { ventricle }\end{array}$

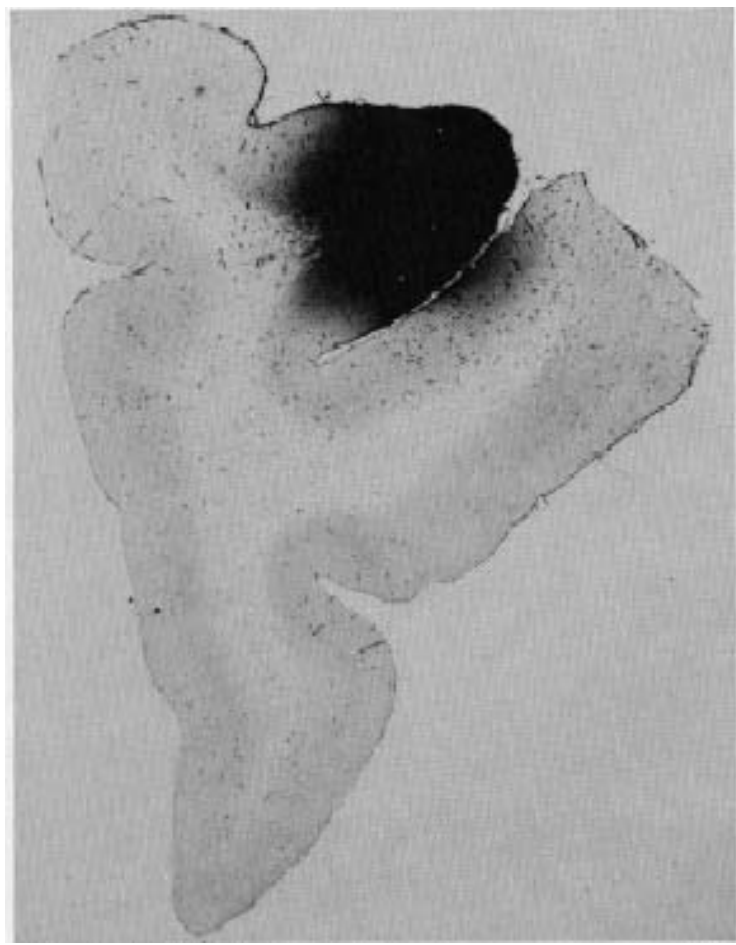

Fig. 2. Bright-field photomicrograph of coronal section through the core of the injection site (dark area) in a case where the mid-dorsal principalis region was injected with HRP. 


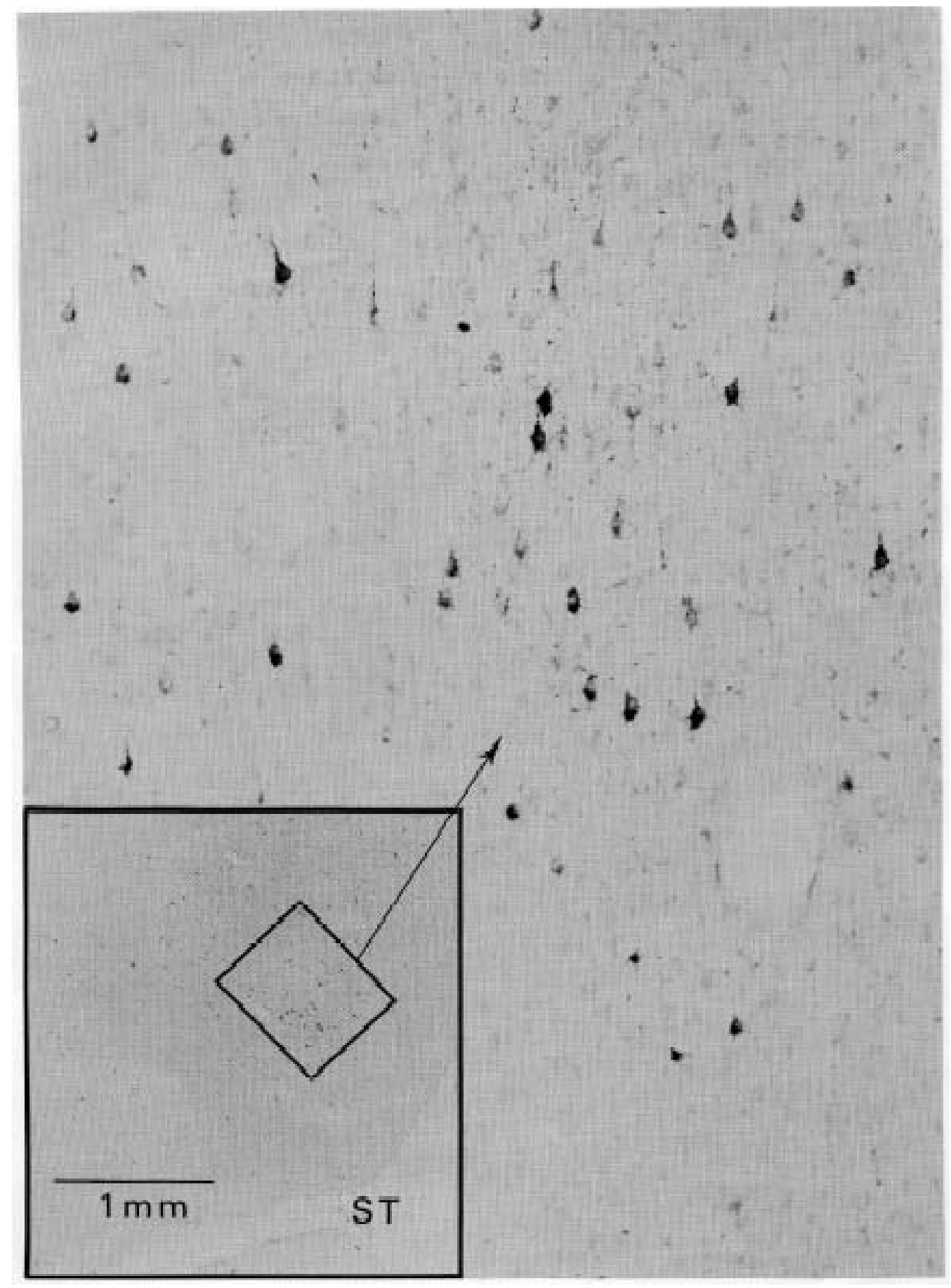

Fig. 8. Bright-field photomicrograph of coronal section through the superior temporal sulcus (inset), showing the distribution of labeled neurons in layer III (magnified region) in the superior temporal gyms' (auditory association) following HRP injection in the rostral part of the principalis region. In this case $25 \%$ of all cortical labeled neurons were in auditory association areas. The extraperikaryal reactionproduct around the labeled cells indicates the presence of intradendritic or anterogradely transported HRP. 


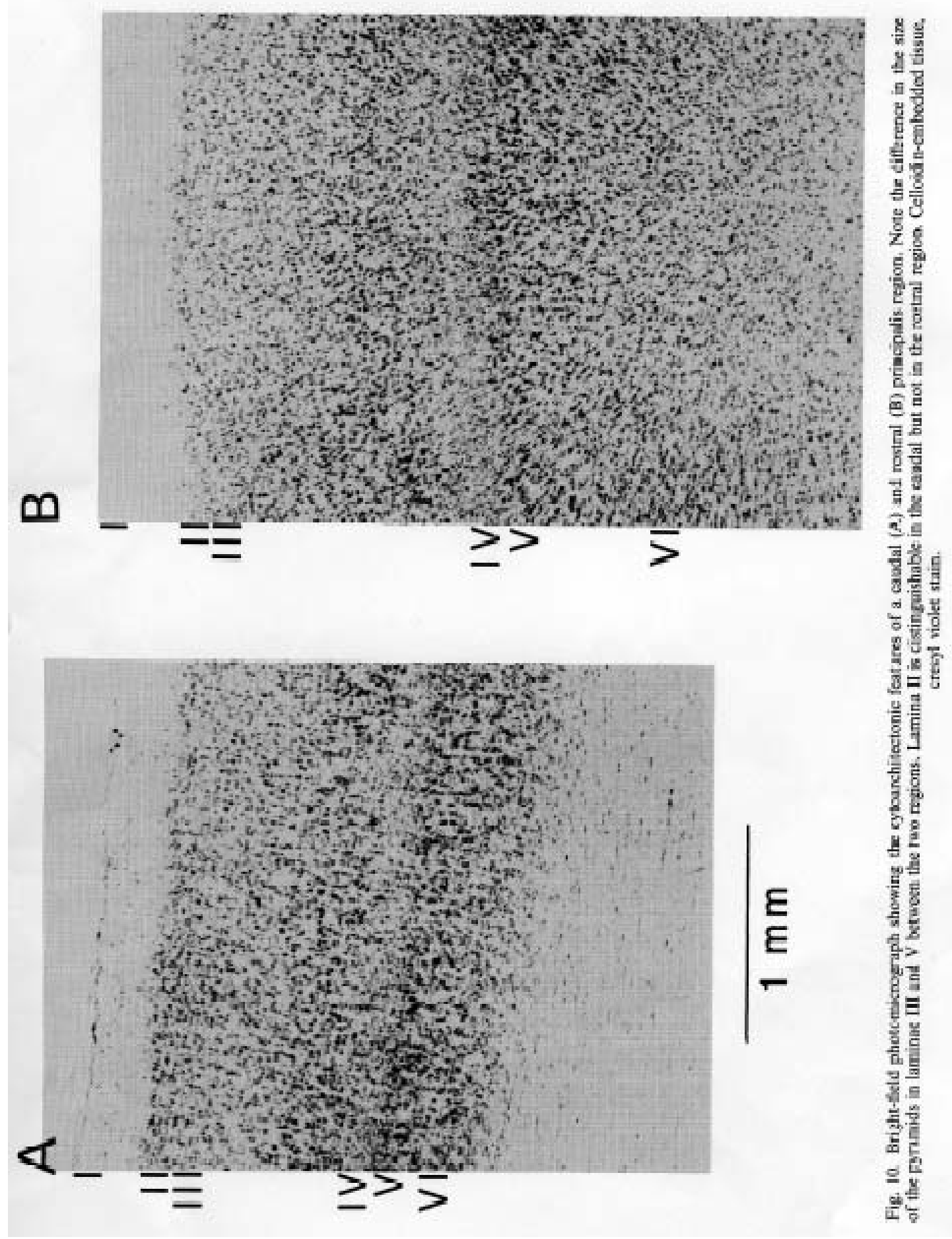


Table I. Distribution of labeled neurons in the macaque cortex following injection of horseradish peroxidase in subdivisions of the principalis region

$$
\begin{array}{ccccc}
\multicolumn{2}{c}{\text { Caudal }} & & \multicolumn{2}{c}{\text { Injection site }} \\
\text { Cortical regions Ventral } & \text { Dorsal } & \text { Ventral } & \text { Dorsal } & \text { Middle }
\end{array}
$$

0.5

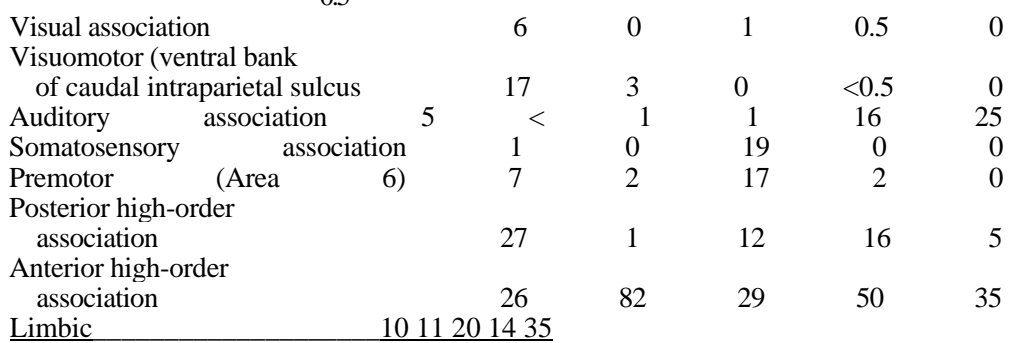

The total number of cortical labeled cells in the five cases was: caudal dorsal, 2241 cells in 47 sections; caudal ventral, 4462 cells in 65 sections; middle dorsal, 7504 cells in 57 sections; middle ventral, 3910 cells in 46 sections; rostral, 2624 cells in 55 sections.

have shown that neurons within area PG respond to visual stimuli and in association with eye movement. ${ }^{47607597}$ However, in recent studies it was shown that the cortex of the caudal ventral intraparietal bank and the dorsolateral parietal cortex are cytoarchitectonically distinguishable regions. ${ }^{68}$ In addition, the ventral sulcal cortex has monosynaptic connections with area $\mathrm{OA}^{83}$ and is also reciprocally connected with the superior colliculus, a preoculomotor center. ${ }^{44,46}$ On the other hand, the dorsolateral portion of area PG receives input primarily from polymodal association regions ${ }^{12,53}$ and projects only sparsely to the superior colliculus. ${ }^{46}$ On the basis of these connectional characteristics, we assume that the cortex of the caudal ventral bank of the intraparietal sulcus has characteristics more closely related with visual-visuomotor functions, whereas the dorsolateral area PG may be considered a higher order association area.

The caudal ventral principalis case had the largest proportion of labeled cells in the ventral bank of the intraparietal sulcus (17\%), followed by the caudal dorsal case $(3 \%)$. In a case with a mid-dorsal principalis injection less than $0.5 \%$ of the labeled cortical cells were observed in the sulcal parietal cortex (Figs 3, 4 and 6), while in the rostral and mid-ventral cases there was no evidence of labeled cells in the above region (Table 1).

\section{Auditory association}

Labeled neurons in auditory association areas were situated in areas TA and TAa. ${ }^{82,90}$ The above regions constitute auditory association regions by virtue of their monosynaptic connections with the primary auditory cortex demonstrated anatomically ${ }^{66,82}$ and on the basis of behavioral ${ }^{48}{ }_{-93}$ and electro-physiologic ${ }^{143+49}{ }_{-} 5$ experiments. Area TA encompasses the superior temporal gyrus and because it is bounded by natural landmarks it is easily identifiable. On the other hand, area TAa occupies the superficial part of the dorsal bank of the superior temporal sulcus and is contiguous with area TPO, a polymodal association cortex in the depths of the upper bank of the superior temporal sulcus. ${ }^{82}$ Because there are no natural boundaries between areas TAa and TPO, cytoarchitectonic differences between the adjacent regions were used to specify the location of labeled neurons. Area TAa is characterized by a predominance in the supragranular layers, prominent IIIc and Va pyramids, and a clear separation between layers V and VI. Area TPO is distinguished from TAa by the less prominent pyramids in layer $\mathrm{V}$ and a wider separation of layers $\mathrm{V}$ and VI. ${ }^{82}$

Labeled neurons in auditory association areas constituted $5 \%$ of all cortical cells projecting to the caudal ventral, approximately $1 \%$ each of those projecting to the caudal dorsal and to the midventral, $16 \%$ of those projecting to the mid-dorsal and $25 \%$ of cells projecting to the rostral principalis site (Table 1, Figs 3-8).

\section{Somatosensory association}

Labeled neurons in Somatosensory association regions were located in the rostral part of the ventral bank of the intraparietal sulcus, in the adjacent cortex laterally (area PF of Von Bonin and Bailey) ${ }^{90}$ in the parietal operculum (areas 1-2), in the dorsal bank at the caudal extent of the lateral fissure (SII) and in the posterior (granular) insula. The above regions have been associated with somatic sensation on the basis of physiologic, anatomic and behavioral experiments (for reviews see Refs 65 and 96).

The mid-ventral principalis case had $19 \%$ of its labeled cells in Somatosensory association areas. The only other site with some labeled neurons in somatosensory association areas (1\%) was the caudal ventral principalis.

\section{Premotor}

Labeled neurons in the premotor area $6^{8}$ were located in the caudal bank and adjacent cortex posterior the arcuate sulcus and were observed following HRP injection in the mid-ventral (17\%), caudal ventral (7\%), mid-dorsal (2\%) and caudal 
dorsal $(2 \%)$ principalis sites. There was no evidence of labeled neurons in the premotor cortex after HRP injection in the rostral principalis region.

\section{High-order association}

Labeled neurons were also seen in regions where the connectivity and physiologic characteristics are not confined to one sensory modality, and where neurons fire in association with sensory-motor tasks. For lack of other descriptive terminology these will be referred to as high-order association regions. Posterior high-order association regions with labeled neurons included the deepest two-thirds of the dorsal bank of the superior temporal sulcus, the medial parietal cortex and the dorsolateral part of area PG. ${ }^{\mathbf{9 0}}$ The inclusion of the above regions in the high-order association category is based on their neuronal response properties ${ }^{5}{ }^{11}$ and on anatomic connectional studies. $1(02<28140,53$

The highest proportion of labeled neurons in posterior high-order association regions was in the case with the most caudal ventral injection $(27 \%)$ and the lowest in the case with the most caudal dorsal injection (1\%). The percentage of neurons projecting to the rest of the principalis sites under study fell in between the above two extremes (Table 1). The two caudal and mid-ventral principalis sites received projections from the depths of the superior temporal sulcus as well as from the inferior parietal lobule and medial parietal cortex. However, the mid-dorsal and rostral sites received more than $95 \%$ of their posterior high-order association projections from the depths of the superior temporal sulcus.

Labeled neurons in frontal high-order association areas were located in Walker's ${ }^{91}$ areas 8, 9, 10 and 46. Neurons in these regions respond to several sensory modalities ${ }^{6}$ and receive input from multiple cortical

regions. The caudal dorsal principalis region

had $82 \%$, the mid-dorsal $50 \%$, the caudal ventral $26 \%$, the mid-ventral $29 \%$, and the rostral case $35 \%$ of its labeled neurons in frontal high-order association regions (Table 1).

\section{Limbic}

Limbic cortical regions as a group share several architectonic, connectional, behavioral and physiologic features. They are cytoarchitectonically characterized as transitional regions between allocortical regions, which have a rudimentary laminar arrangement, and isocortical areas, which are organized into six cortical laminae. Anatomically limbic cortical regions have connections with subcortical limbic structures. ${ }^{2728}$ ${ }_{6167727377}$ Physiologically and behav-iorally limbic regions seem to be involved in auto-nomic responses and the state of the internal milieu of the organism. ${ }^{21}{ }_{-} 930$

Limbic cortical regions where labeled neurons were observed included the cingulate and retrosplenial cortex, regions of the caudal orbitofrontal cortex, the temporal pole and the anterior insula. These regions are included in Walker's ${ }^{91}$ areas 24, 25, 13 and 14 The highest percentage of labeled neurons was noted following injection of HRP in the most rostral (35\%), the smallest in the most caudal ventral $(10 \%)$ and caudal dorsal $(11 \%)$, while an intermediate percentage was noted following HRP injection of the mid-dorsal $(14 \%)$ or mid-ventral $(20 \%)$ principalis sites.

Over $95 \%$ of neurons in limbic cortical regions projecting to both caudal principalis sites, and $59 \%$ of those projecting to the mid-ventral site were situated in the cingulate cortex (Figs 3-5). However, the cingulate contributed a considerably smaller proportion of the limbic projections to the mid-dorsal (24\%) or rostral (13\%) principalis sites (Figs 6 and 7). These latter sites received most of their limbic projections from the caudal orbitofrontal cortex and from the temporal pole.

\section{Laminar distribution of labeled neurons}

Labeled cortical cells were located in cortical layers III, V and VI. The distribution of labeled neurons in the above layers differed from one cortical region to the other in a manner consistent from case to case. Because of the similar trend in the distribution of labeled cells by layer in each functional category in the five HRP cases, the results were pooled and are shown graphically in Fig. 9. Because of the difficulty in determining the border between layers $\mathrm{V}$ and VI, labeled neurons in the infragranular layers were considered together.

Most labeled neurons were found in cortical layer III. The supragranular preponderance of labeling was most pronounced in the visual and somatosensory unimodal association areas, and less marked in auditory, high-order association and limbic cortical regions. This general trend is consistent with previous findings. $^{2}$
100
HI 80
o 60
$\begin{array}{ll}\text { Q } & 60 \\ \text { uj } & 40\end{array}$
บ 40
20

\section{VASS IP AU PM HOA LI CORTICAL REGIONS}

Fig. 9. Histogram showing the percentage of labelled neurons in lamina III and in laminae $\mathrm{V}$ and VI in visual association (VA), somatosensory (SS), ventral bank of intraparietal sulcus (IP), auditory (AU), premotor (PM), high-order association (HOA) and limbic (LI) cortical regions. The black (lamina III), and white (laminae V, VI) bars in each region add up to $100 \%$. Note that the percentage of neurons in layer HI decreases from visual association to high-order association to limbic cortical regions. For description of regions included in each category see text. 


\section{Cytoarchitectonic characteristics}

The caudal and middle principalis regions are within area 46 and the rostral is within area $10 .^{91}$ The caudal regions show the most developed laminar organization. They have a greater cell density in the supragranular layers than in the infragranular layers. They are further characterized by a well-developed granular layer IV, medium-sized pyramidal cells in layers $\mathrm{I} \mathrm{He}$ and $\mathrm{Va}$ and a discernible separation between layers V and VI and between layers II and III. The neurons in the caudal region show a columnar arrangement throughout the six cortical layers. In progressively more rostral principalis regions the pyramids in layer III are small and the infragranular layer $\mathrm{V}$ is the most prominent layer. The granular layer IV is smaller in rostral than in caudal regions and the neurons do not show a columnar arrangement. Moreover, the distinction between layers II and III and between V and VI fades from a mid to rostral principalis regions (Fig. 10).

\section{DISCUSSION}

The results indicate that the cortex along the banks of the principalis sulcus receives a substantial proportion of its projections from neighboring prefrontal regions. In addition input originating in limbic, pre-motor, posterior high-order association and in auditory, somatosensory, visuomotor and visual association areas also reaches this region. However, neurons situated in functionally distinct cortical regions project preferentially to specific sites within the principalis region. For example, input from the peri-striate visual association cortices terminates mostly in the caudal-half of the principalis, especially along the ventral bank. Most of the labeled neurons are situated within medial and lateral preoccipital regions (perhaps corresponding to areas V3 and V4) which were recently implicated in visual spatial tasks. ${ }^{57}$ Since some of these neurons fire when monkeys direct their gaze towards the neuronal visual receptive field, ${ }^{13}, 15$ peristriate input to the principalis may also have visuomotor characteristics. In this context it is interesting that projections from the ventral bank of the intraparietal sulcus, a region associated on connectional $^{44}{ }_{-}^{46}$ and physiologic grounds ${ }^{84}$ as a visuomotor region, are also preferentially directed to the caudal part of the principalis, particularly to its ventral bank. $^{42}$ Neurons in the caudal bank of the intraparietal sulcus also have complex firing properties in association with eye movements directed at stimuli which have motivational significance for the animal. ${ }^{23>47}{ }^{6075}$ The projection from this caudal intraparietal cortex to the principalis area may provide an anatomic basis for the complex and task-related visual responses in the caudal principalis region 163135365471808187

With regard to behavior, subregions of the dorsolateral prefrontal cortex have been associated with delayed response and alternation tasks. These complex tasks, based on the intervention of a delay period between the presentation of stimuli and the required response, seem to depend, on a combination of sensory, spatial, proprioceptive and mnemonic factors. ${ }_{1819}<{ }^{32,34}>5877-79$ Further behavioral and physiologic studies have shown that the middle-third and caudal part of the principalis are the critical sites for delayed response tasks. ${ }^{56,85}$ The afferent input from peristriate and intraparietal regions may subserve the visuospatial and visuomotor aspects of delayed responses. In addition, projections from somatosensory, premotor and limbic cortices to the middle and caudal principalis may contribute to the additional aspects of delayedresponse tasks. Somatosensory association regions including areas PF, 1, 2, SII, and the granular insula, project mostly to the ventral bank at the middle extent of the principalis. Input from the premotor (area 6) cortex reaches both banks of the caudal two-thirds of the principalis and is also preferentially directed to the mid-ventral principalis region, to the same site which receives the somatosensory input. The premotor cortex, with its known reciprocal connections with the motor cortex, ${ }^{28}{ }^{69}$ may provide a link underlying the execution phase of tasks supported by the principalis cortex. Indeed a distinct class of neurons in the caudalhalf of the principalis fires in association with the motor aspect of a task. ${ }^{31,37,38}$ It is of interest that the part of the principalis cortex which is most essential for delayed-response tasks is also the part which preferentially receives visuomotor, premotor and somatosensory projections.

All principalis sites injected with HRP received some input from auditory association regions. However, the relative proportion of labeled neurons in auditory association regions was much higher in cases where the projection was directed to the rostral tip, and to the mid-dorsal bank. All principalis sites received some input from limbic cortical regions, originating in the cingulate, the orbitofrontal cortex, the anterior insula and the temporal pole. The proportion of all projecting neurons from limbic cortical regions increased from a caudal to rostral extent within the principalis sulcus, irrespective of whether the HRP injection was in the ventral or dorsal bank. In addition, the origin of the limbic input to each principalis site also differed. The rostral and mid-dorsal sites, which were the main targets of projections from auditory association regions, received the majority of their limbic projections from the caudal orbitofrontal cortex, and from the temporal pole and less from the cingulate cortex. On the other hand, the majority of neurons in limbic cortical regions projecting to the caudal and mid-ventral principalis sites were situated in the cingulate cortex. The significance of the diversity of origin of limbic input to the two groups of principalis sites is not known but suggests that the limbic input to the two groups of sites may subserve different functions. It 
is possible that input originating in the cingulutc cortex may underlie mnemonic processes operative in delayed response tasks. It should be noted that cingulotomy interferes with the acquisition of delayed alternation tasks ${ }^{74}$ and that neurons in the anterior cingulate cortex fire in association with different aspects of delayed response tasks much like principalis neurons do. ${ }^{17}$

The principalis sites with the heaviest input from auditory regions received little or none of their cortical input from visual, visuomotor or somatosensory regions. The premotor cortex contributed only a small proportion of all neurons which projected to the mid-dorsal principalis site, while the rostral region seemed to lack premotor projections. Moreover, the premotor input to the mid-dorsal site originated in dorsal area 6 , a region where the trunk is represented. In contrast, the other principalis sites, and particularly the ventral bank at the most caudal and middle extent of the sulcus, received a significant proportion of their premotor projections from regions which represent both the trunk and the head and neck. In addition, input from high-order association regions to the main auditory recipient principalis sites originated primarily from the depths of the superior temporal sulcus. On the other hand the other principalis sites also received some of their input from the inferior parietal lobule and from the medial parietal cortex, regions thought to have some role in spatial performance. ${ }^{22,45,57}$

\section{Concluding remarks}

The data presented suggest that the different principalis regions may have different functions. The caudal and mid-ventral principalis sites may be involved in directing the eyes to sensory stimuli which are relevant for a specific task and in delayed alternation tasks. On the other hand the neural processing in the mid-dorsal and rostral principalis regions, the main auditory recipient regions, may be different and difficult to specify at this time. But it should be noted that impairment on auditory discrimination and delayed response tasks following frontal cortical lesions have long been dissociated. ${ }^{20}{ }^{94}$ However, because the lesions were large in earlier studies, no determination of specific prefrontal sites underlying auditory discrimination could be made. The main auditory recipient principalis regions may be involved in more generalized alerting mechanisms. The spatially diffuse but more accessible auditory input, along with a substantial input from frontal limbic structures, may subserve this aspect of frontal lobe function.

Acknowledgements-This research was supported by grants NS 06719, BNS 83-15411, Seed Grant GRS-691 (H.B.) and NS 09211, NS 07011, NS 20285 and the Javits Neuroscience Investigator Award (M-M. M.). We thank Mr. R. Plourde and Ms. T. Martin for technical assistance, Ms. K. Castignetti and Ms. L. Christie for secretarial assistance and Dr. A. Galaburda for providing a Nissl-stained series used in this study.

\section{REFERENCES}

1. Ades H. W. and Felder R. (1942) The acoustic area of the monkey (Macaca mulatto \}. J. Neurophysiol. 5, 49-54.

2. Barbas H. and Mesulam M-M. (1981) Organization of afferent input to subdivisions of area 8 in the rhesus monkey. $J$. comp. Neurol. 200, 407-431.

3. Battig K., Rosvold H. E. and Mishkin M. (1962) Comparison of the effects of frontal and caudate lesions on discrimination learning in monkeys. «l. comp, Physiol. Psychol. 55, 458-463.

4. Bauer R. H. and Fuster J. M. (1976) Delayed-matching and delayed-response deficit from cooling dorsolateral prefrontal cortex in monkeys. J. comp. Physiol. Psychol. 90, 293-302.

5. Benevento L. A., Fallen J., Davis B. J. and Rezak M. (1977) Auditory-visual interactions in single cells in the cortex of the superior termporal sulcus and the orbital frontal cortex of the macaque monkey. Expl Neurol. 57, 849-872.

6. Bignall K. E. and Imbert M. (1969) Polysensory and cortico-cortical projections to frontal lobe of squirrel and rhesus monkeys. Electroencep. din. Neurophysiol. 26, 206-215.

7. Blum R. A. (1952) Effects of subtotal lesions of frontal granular cortex on delayed reaction in monkeys. Archs Neurol. Psychiat., Chicago 67, 375-386.

8. Brodmann K. (1905) Beitrage zur histologischen Lokalisation der Grosshirnrinde. III. Mitteilung: Die Rindenfelder der neideren Affen. J. Psychol. Neurol., Lpz. 4, 177-226.

9. Butters N. and Pandya D. N. (1969) Retention of delayed-alternation: effect of selective lesion of sulcus principalis. Science, N.Y. 165, 1271-1273.

10. Chavis D. A. and Pandya D. N. (1976) Further observations on corticofrontal connections in the rhesus monkey. Brain Res. $117,369-386$.

11. Desimone R. and Gross C. G. (1979) Visual areas in the temporal cortex of the macaque. Brain Res. 178, 363-380.

12. Divac L., LaVail J. H., Rakic P. and Winston K. R. (1977) Heterogeneous afferents to the inferior parietal lobule of the rhesus monkey revealed by the retrograde transport method. Brain Res. 123, 197-207.

13. Fischer B. and Boch R. (1981) Selection of visual targets activates prelunate cortical cells in trained rhesus monkey. Expl Brain Res. 41, 431-433.

14. Fischer B. and Boch R. (1981) Enhanced activation of neurons in prelunate cortex before visually guided saccades of trained rhesus monkeys. Expl Brain Res. 44, 129-137.

15. Fischer B. and Boch R. (1982) Modifications of presaccadic activation of neurons in the extrastriate cortex during prolonged training of rhesus monkeys in a visuo-oculomotor task. Neurosci. Lett. 30, 127-131.

16. Funahashi S. (1983) Responses of monkey prefrontal neurons during a visual tracking task reinforced by substantia innominata self-stimulation. Brain Res. 276, 267-276.

17. Fuster J. M. (1973) Unit activity in prefrontal cortex during delayed-response performance: neuronal correlates of transient memory. I. Neurophysiol. 36, 61-78.

18. Fuster J. M. and Alexander G. E. (1971) Neuron activity related to short-term memory. Science, N.Y. 173, 652-654. 
19. Goldman I*. S., Rosvold II. Iv., Vest B. and Galkin T. W. (1971) Analysis of the delayed alternation deficit produced by dorsolateral prefrontal lesions in the rhesus monkey. ./. conip. Physiol. PsychoL 77, 212220.

20. Gross C. G. and Weiskrant/ L. (1962) Evidence for dissociation of impairment on auditory discrimination and delayed response following lateral frontal lesions in monkeys. Expl NeuroL 5, 453476.

21. Hodman B. L. and Rasmussen T. (1953) Stimulation studies of insular cortex of Macaca mulutta. J. NeurophysioL 16, 343 351.

22. Hyvarinen J. (1982) Posterior parietal lobe of the primate brain. Physiol. Rev. 62, 10601129.

23. Hyvarinen J. and Poranen A. (1974) Function of the parietal associative area 7 as revealed from cellular discharges in alert monkeys. Brain 97, 673692.

24. Ho S. I. (1982) Prefrontal unit activity of macaque monkeys during auditory and visual reaction time tasks. Brain Res. 247,39-117.

25. Jacobsen C. F. (1936) Studies of cerebral function in primates: 1. The functions of the frontal association area in monkeys. Comp. Psychol. Monogr. 13, 3-60.

26. Jacobson S. and Trojanowski J. Q. (1977) Prefrontal granular cortex of the rhesus monkey. I. Intrahemispheric cortical afferents. Brain Res. 132, 209-233.

27. Johnson T. N., Rosvold H. E. and Mishkin M. (1968) Projections from behaviorally defined sectors of the prefrontal cortex to the basal ganglia, septum, and diencephalon of the monkey. Expl NeuroL 21, 20-34.

28. Jones E. G. and Powell T. P. S. (1970) An anatomical study of converging sensory pathways within the cerebral cortex of the monkey. Brain 93, 793-820.

29. Kaada B. R. (1960) Cingulate, posterior orbital, anterior insular and temporal pole cortex. In Neurophysiology (ed. Magoun, H. W.), pp. 1345-1372. Waverly Press, Baltimore.

30. Kaada B. R., Pribram K. H. and Epstein J. A. (1949) Respiratory and vascular responses in monkeys from temporal pole, insula, orbital surface and cingulate gyrus. J. NeurophysioL 12, 348-356.

31. Kojima S. (1980) Prefrontal unit activity in the monkey: relation to visual stimuli and movements. Expl NeuroL 69, 110-123.

32. Kojima S. and Goldman-Rakic P. S. (1982) Delay-related activity of prefrontal neurons in rhesus monkeys performing delayed response. Brain Res. 248, 43-49.

33. Kojima S. and Goldman-Rakic P. S. (1984) Functional analysis of spatially discriminative neurons in prefrontal cortex of rhesus monkey. Brain Res. 291, 229-240.

34. Kojima S., Kojima M. and Goldman-Rakic P. S. (1982) Operant behavioral analysis of memory loss in monkeys with prefrontal lesions. Brain Res. 248, 51-59.

35. Komatsu H. (1982) Prefrontal unit activity during a color discrimination task with GO and NO-GO responses in the monkey. Brain Res. 244, 269-277.

36. Kubota K. and Funahashi S. (1982) Direction-specific activities of dorsolateral prefrontal and motor cortex pyramidal tract neurons during visual tracking. J. NeurophysioL 47, 362-376.

37. Kubota K., Iwamoto T. S. and Suzuki H. (1974) Visuokinetic activities of primate prefrontal neurons during delayed-response performance. J. NeurophysioL 37, 1197-1212.

38. Kubota K. and Niki H. (1971) Prefrontal cortical unit activity and delayed alternation performance in monkeys. $J$. NeurophysioL 34, 337-347.

39. Kubota K., Tonoike M. and Mikami A. (1980) Neuronal activity in the monkey dorsolateral prefrontal cortex during a discrimination task with delay. Brain Res. 183, 29-42.

40. Kuypers H. G. J. M., Szwarcbart M. R., Mishkin M. and Rosvold H. E. (1965) Occipitotemporal cortico-cortical connections in the rhesus monkey. Expl NeuroL 11, 245-262.

41. La Vail J. H. (1975) Retrograde cell degeneration and retrograde transport techniques. In The Use of Axonal Transport for Studies of Neuronal Connectivity (eds Cowan W. M. and Cuenod M.), pp. 217-248. Elsevier, New York.

42. Leichnetz G. R. (1980) An intrahemispheric columnar projection between two cortical multisensory convergence areas (inferior parietal lobule and prefrontal cortex): an anterograde study in macaque using HRP gel. Neurosci. Lett. 18, 119-124.

43. Leinonen L., Hyvarinen J. and Sovijarvi A. R. A. (1980) Functional properties of neurons in the temporo-parietal association cortex of awake monkey. Expl Brain Res. 39, 203-215.

44. Lobeck L. J., Lynch J. C. and Hayes N. L. (1983) Neurons in attention-related regions of the cerebral cortex which project to intermediate and deep layers of superior colliculus of the rhesus monkey. Soc. Neurosci. Abstr. 9, 751.

45. Lynch J. C. (1980) The functional organization of posterior parietal association cortex. Behav. Brain Sci. 3, 485-534.

46. Lynch J. C. and Graybiel A. M. (1983) Comparison of afferents traced to the superior colliculus from the frontal eye fields and from two sub-regions of area 7 of the rhesus monkey. Soc. Neurosci. Abstr. 9, 750.

47. Lynch J. C., Mountcastle V. B., Talbot W. H. and Yin T. C. T. (1977) Parietal lobe mechanisms for directed visual attention. J. NeurophysioL 40, 362-389.

48. Massopust L. C, Jr., Barnes J. W. and Verdura J. (1965) Auditory frequency discrimination in cortically ablated monkeys. J. Audit. Res. 5, 85-93.

49. Merzenich M. M. and Brugge J. F. (1973) Representation of the cochlear partition on the superior temporal plane of the macaque monkey. Brain Res. 50, 275-296.

50. Mesulam M-M. (1978) Tetramethyl benzidine for horseradish peroxidase neurohistochemistry: a non-carcinogenic blue reaction-product with superior sensitivity for visualizing neural afferents and efferents. J. Histochem. Cytochem. 26, 106117.

51. Mesulam M-M. (1982) Principles of horseradish peroxidase neurohistochemistry and their applications for tracing neural pathways-Axonal transport, enzyme histochemistry and light microscopic analysis. In Tracing Neural Connections with Horseradish Peroxidase (ed. Mesulam M-M.), pp. 1-151. John Wiley, Chichester.

52. Mesulam M-M., Hegarty E., Barbas H., Carson K. A., Gower E. C., Knapp A. G., Moss M. B. and Mufson E. J. (1980) Additional factors influencing sensitivity in the tetramethyl benzidine method for HRP neurohistochemistry. J. Histochem. Cytochem. 28, 1255-1259.

53. Mesulam M-M., Van Hoesen G. W., Pandya D. N. and Geschwind N. (1977) Limbic sensory connections of the inferior parietal lobule (area PG) in the rhesus monkey: a study with a new method for horseradish peroxidase histochemistry. Brain Res. 136, 393-414. 
54. Mikami A., Ho S. and Kubota K. (1982) Visual properties of dorsolateral prefrontal neurons during visual fixation (ask. J. Neurophysiol. 47, 593-605.

55. Miller J. M., Sutton D., Pfingst B., Ryan A. and Beaton R. (1972) Single cell activity in the auditory cortex of rhesus monkeys: behavioral dependency. Science, N.Y. 177, 449-451.

56. Mishkin M. (1957) Effects of small frontal lesions in delayed alternation in monkeys. J. Neurophysiol. 20, 615-622.

57. Mishkin M., Lewis M. E. and Ungerleider L. G. (1982) Equivalence of parieto-preoccipital subareas for visuospatial ability in monkeys. Behav. Brain Res. 6, 41-55.

58. Mishkin M. and Manning F. J. (1978) Non-spatial memory after selective prefrontal lesions in monkeys. Brain Res. 143, 313-323.

59. Mishkin M. and Pribram K. H. (1955) Analysis of the effects of frontal lesions in monkeys. J. comp. Physiol. Psychol. 48, $492-495$.

60. Mountcastle V. B., Lynch J. C. and Georgopoulos A. (1975) Posterior parietal association cortex of the monkey: command functions for operations within extrapersonal space. /. Neurophysiol. 38, 871-908.

61. Nauta W. J. H. (1964) Some efferent connections of the prefrontal cortex in the monkey. In The Frontal Granular Cortex and Behavior (eds Warren J. M. and Akert K.), pp. 397-409. McGraw-Hill, New York.

62. Nauta W. J. H. (1971) The problem of the frontal lobe: a reinterpretation. /. Psychiat. Res. 8, 167-187.

63. Niki H. (1974) Prefrontal unit activity during delayed alternation in the monkey. II. Relation to absolute versus relative direction of response. Brain Res. 68, 197-204.

64. Niki H. and Watanabe M. (1979) Prefrontal and cingulate unit activity during timing behavior in the monkey. Brain Res. Ill, 213-224.

65. Norrsell U. (1980) Behavioral studies of the somatosensory system. Physiol. Rev. 60, 327-354.

66. Pandya D. N., Hallet M. and Mukherjee S. K. (1969) Intra- and interhemispheric connections of the neocortical auditory system in the rhesus monkey. Brain Res. 14, 49-65.

67. Pandya D. N. and Kuypers H. G. J. M. (1969) Cortico-cortical connections in the rhesus monkey. Brain Res. $13,13-36$.

68. Pandya D. N. and Seltzer B. (1982) Intrinsic connections and architectonics of posterior parietal cortex in the rhesus monkey. I. comp. Neurol. 204, 196-210.

69. Pandya D. N. and Vignolo L. A. (1971) Intra- and interhemispheric projections of the precentral, premotor and arcuate areas in the rhesus monkey. Brain Res. 26, 217-233.

70. Petrides M. and Pandya D. N. (1984) Projections to the frontal cortex in the posterior parietal region in the rhesus monkey. J. comp. Neurol. 228, 105-116.

71. Pigarev I. N., Rizzolatti G. and Scandolara C. (1979) Neurons responding to visual stimuli in the frontal lobe of macaque monkeys. Neurosci. Lett. 12, 207-212.

72. Potter H. and Nauta W. J. H. (1979) A note on the problems of olfactory associations of the orbitofrontal cortex in the monkey. Neuroscience 4, 361-367.

73. Pribram K. H., Lennox M. A. and Dunsmore I. H. (1950) Some connections of the orbito-frontotemporal limbic and hippocampal areas of Macaca mulatta. J. Neurophysiol. 13, 127-135.

74. Pribram K. H., Wilson W. A. Jr and Connors J. (1962) Effects of lesions of the medial forebrain on alternation behavior of rhesus monkeys. Expl Neurol. 6, 36-47.

75. Robinson D. L., Goldberg M. E. and Stanton G. B. (1978) Parietal association cortex in the primate: sensory mechanisms and behavioral modulation. /. Neurophysiol. 41, 910-932.

76. Rosene D. L. and Mesulam M-M. (1978) Fixation variables in horseradish peroxidase neurohistochemistry. 1. The effect of fixation time and perfusion procedures upon enzyme activity. J. Histochem. Cytochem. 26, 28-39.

77. Rosene D. L. and Van Hoesen G. W. (1977) Hippocampal efferents reach widespread areas of cerebral cortex and amygdala in the rhesus monkey. Science, N.Y. 198, 315-317.

78. Rosenkilde C. E., Bauer R. H. and Fuster J. M. (1981) Single cell activity in ventral prefrontal cortex of behaving monkeys. Brain Res. 209, 375-394.

79. Rosenkilde C. E., Rosvold H. E. and Mishkin M. (1981) Time discrimination with positional responses after selective prefrontal lesions in monkeys. Brain Res. 210, 129-144.

80. Sakai M. (1974) Prefrontal unit activity during visually guided lever pressing reaction in the monkey. Brain Res. 81, 297309.

81. Schechter P. B. and Murphy E. H. (1975) Response characteristics of single cells in squirrel monkey frontal cortex. Brain Res. 96, 66-70.

82. Seltzer B. and Pandya D. N. (1978) Afferent cortical connections and architectonics of the superior temporal sulcus and surrounding cortex in the rhesus monkey. Brain Res. 149, 1-24.

83. Seltzer B. and Pandya D. N. (1980) Converging visual and somatic sensory cortical input to the intraperietal sulcus of the rhesus monkey. Brain Res. 192, 339-351.

84. Shibutani H., Sakata H. and Hyvarinen J. (1984) Saccade and blinking evoked by microstimulation of the posterior parietal association cortex of the monkey. Expl Brain Res. 55, 1-8.

85. Stamm J. S. (1969) Electrical stimulation of monkeys' prefrontal cortex during delayed response performance. J. comp. Physiol. Psychol. 67, 535-546.

86. Stepien I. and Stamm J. S. (1970) Locomotor delayed response in frontally ablated monkeys. Acta neurobiol. exp. $30,13-18$.

87. Suzuki H. and Azuma M. (1977) Prefrontal neuronal activity during gazing at a light spot in the monkey. Brain Res. 126, 491505 .

88. Ungerleider L. G. and Mishkin M. (1982) Two cortical visual systems. In Analysis of Visual Behavior (eds Ingle D. J., Goodale M. A. and Mansfield R. J. W.), pp. 549-586. The MIT Press, Cambridge.

89. Van Essen D. C. (1979) Visual areas of the mammalian cerebral cortex. A. Rev. Neurosci. 2, 227-263.

90. Von Bonin G. and Bailey P. (1947) The Neocortex of Macaca Mulatta. The University of Illinois Press, Urbana.

91. Walker E. (1940) A cytoarchitectural study of the prefrontal area of the macaque monkey. /. comp. Neurol. $98,59-86$.

92. Watanabe M. (1981) Prefrontal unit activity during delayed conditional discriminations in the monkey. Brain Res. 225, 51-65.

93. Wegener J. G. (1964) Auditory discrimination behavior of brain-damaged monkeys. J. Audit. Res. 4, 227-259. 
94. Weiskrantz L. and Mishkin M. (1958) Effects of temporal and frontal cortical lesions on auditory discrimination in monkeys. Brain 81, 406-414

95. Woolsey C. N. (1981) Cortical Sensory Organization. Vol. 2, Multiple Visual Areas. Humana Press, Clifton, New Jersey.

96. Woolsey C. N. (1981) Cortical Sensory Organization. Vol. 1, Multiple Somatic Areas. Humana Press, Clifton, New Jersey.

97. Yin T. C. and Mountcastle V. B. (1977) Visual input to the visuomotor mechanisms of the monkey's parietal lobe. Science, N.Y. 197, 1381-1383.

98. Zeki S. M. (1978) Functional specialization in the visual cortex of the rhesus monkey. Nature 274, 423-428.

(Accepted 16 January 1985) 